\title{
Formação de professores na área de Educação Ambiental: uma análise dos anais da ANPEd (2009-2011)
}

\author{
Júlia de Moura Martins Guimarães ${ }^{1}$ \\ Jacqueline Magalhães Alves ${ }^{2}$
}

Resumo: O presente trabalho buscou levantar como a formação de professores em Educação Ambiental (EA) tem sido abordada nas últimas reuniões da Associação Nacional de Pós-Graduação e Pesquisa em Educação (ANPEd), de modo a tecer um diálogo desde o horizonte interpretativo da hermenêutica filosófica. Procedeu-se à leitura de todos os resumos publicados pelo Grupo de Trabalho 22 nos encontros nacionais da ANPEd em 2009, 2010 e 2011, a partir dos quais foram selecionados sete textos completos. Empregou-se o método de análise de conteúdo, por meio do qual foram identificadas as seguintes categorias: Críticas ao reducionismo da EA; EA crítica como possibilidade de superação da EA vigente; Experiências de EA mediadas pela pesquisa-ação; e Desafios na operacionalização da legislação que institui a EA. Concluiu-se que essas temáticas refletem o quanto os pesquisadores que se ocupam da formação docente em EA estão preocupados em denunciar a situação atual do educador ambiental.

Palavras-chave: Formação docente. Hermenêutica. Educação Ambiental Crítica.

\section{Teacher education in the field of Environmental Education: an analysis of ANPEd proceedings (2009-2011)}

\begin{abstract}
This study aimed to survey how teacher education in Environmental Education (EE) has been addressed in the last meetings of the National Association of Graduate Studies and Research in Education (ANPEd), in order to weave a dialogue based on the interpretive horizon of philosophical hermeneutics. All abstracts published by Work Group 22 at ANPEd national meetings in 2009, 2010 and 2011 were read and then seven full texts were selected. Using the content analysis method, we identified the following categories: Criticism of EE reductionism; Critical $\mathrm{EE}$ as a possibility of overcoming the current EE; EE experiences

\footnotetext{
1 Mestranda em Educação pela Universidade Federal de Lavras(UFLA),Lavras,Brasil, judemoura@hotmail.com

2 Professora de Educação na Universidade Federal de Lavras (UFLA) ,Lavras,Brasil, jacque@ded.ufla.br
} 
mediated by action research; and Operational challenges in the legislation that establishes EE. It was concluded that these themes reflect the extent to which researchers that work with teacher education in EE are concerned about denouncing the current situation of environmental educators.

Keywords: Teacher education. Hermeneutics. Critical Environmental Education.

\section{Formación de profesores en el área de Educación Ambiental: un análisis de los anales de la ANPEd (2009-2011)}

Resumen: El presente trabajo intentó levantar cómo se ha abordado la formación de profesores en Educación Ambiental (EA) en las últimas reuniones de la Asociación Nacional de Posgrado e Investigación en Educación (ANPEd - Associação Nacional de Pós-graduação e Pesquisa em Educação), a modo de tejer un diálogo desde el horizonte interpretativo de la hermenéutica filosófica. Se procedió a la lectura de todos los resúmenes publicados por el Grupo de Trabajo 22 en los encuentros nacionales de la ANPEd en 2009, 2010 y 2011, a partir de los cuales se seleccionaron siete textos completos. Se empleo el método de análisis de contenido, por medio del cual se identificaron las siguientes categorías: Críticas al reduccionismo de la EA; EA crítica como posibilidad de superación de la EA vigente; Experiencias de EA mediadas por la investigación-acción; y Desafíos en la operacionalización de la legislación que instituye la EA. Se concluye que estas temáticas reflejan cuánto los investigadores que se ocupan de la formación docente en EA están preocupados en denunciar la situación actual del educador ambiental.

Palabras clave: Formación docente. Hermenéutica. Educación Ambiental Crítica.

\section{Introdução}

Desde 1999, quando a Lei $\mathrm{n}^{\circ}$ 9.795, que institui a Política Nacional de Educação Ambiental, foi decretada no Brasil, a Educação Ambiental (EA) tem ganhado mais visibilidade, passando a ser amplamente discutida nos espaços formais e não formais de educação do País. Isso passa a ficar mais evidente a partir de 2001, com a realização do I Encontro de Pesquisa em Educação Ambiental (EPEA), seguido do surgimento da Associação Nacional de PósGraduação e Pesquisa em Ambiente e Sociedade (ANPPAS) no ano seguinte e da criação, em 2003, de um grupo de estudos sobre o tema Educação Ambiental na 
Associação Nacional de Pós-Graduação e Pesquisa em Educação (ANPEd). Esse grupo de estudos vigorou durante dois anos e, a partir de 2005, obteve o status de grupo de trabalho, também conhecido como GT 22 (CARVALHO; FARIAS, 2010).

A Política Nacional de Educação Ambiental (PNEA) foi criada para desenvolver e orientar ações no âmbito da EA envolvendo instituições que atuam na educação formal, como as escolas públicas e privadas e os espaços de educação não formal, englobando os meios de comunicação de massa, organizações não governamentais e empresas. Entre as linhas de atuação, ressalta a necessidade de preparar e formar pessoas que possam viabilizar as ações previstas, apontando "a incorporação da dimensão ambiental na formação, especialização e atualização dos educadores de todos os níveis e modalidades de ensino" (BRASIL, 1999, p. 2) como ferramenta fundamental na efetivação prática da Educação Ambiental. Portanto, a inclusão de conteúdos ambientais na formação de educadores, além da relevância por sua dimensão ética e cidadã, possui, através da PNEA, legitimação jurídica, configurando-se como uma temática de estudo e pesquisa de extrema importância.

O reconhecimento da relevância desse assunto tem sido ressaltado por pesquisadores da área. Carvalho e Farias (2010), em levantamento sobre o que tem sido produzido em $\mathrm{EA}$ na última década, apontam a categoria EA na formação de professores/educadores como expressiva, já que figurou entre as cinco temáticas mais discutidas entre 2001 e 2009, considerando-se os trabalhos apresentados nos encontros da ANPEd e ANPPAS e nos EPEAs ao longo do referido período.

Tendo em conta essas considerações, o objetivo do presente artigo consiste em fazer um levantamento de como a temática da formação de professores/educadores em EA tem sido abordada pelos trabalhos publicados no GT 22 das reuniões nacionais da ANPEd no último triênio (2009-2011). Witter (2005) destaca a importância de trabalhos que analisam a produção científica de uma área específica - como os de revisão de literatura - por contribuírem para o desenvolvimento da ciência, uma vez que permitem a

avaliação dos saberes produzidos em determinado campo do conhecimento, apontando a quantidade e a qualidade do que tem sido produzido de relevante, bem como os problemas e lacunas.

A escolha pelas publicações da ANPEd deve-se ao reconhecimento que essa organização possui no País. Segundo Carvalho e Farias (2010, p. 1):

A ANPEd é a associação científica mais antiga e prestigiada em Educação no Brasil e desde 1976 congrega associados em âmbito nacional. Seu objetivo é a consolidação do ensino de pós-graduação e da pesquisa educacional no país. Atualmente, as Reuniões da ANPEd são consideradas pela Coordenação de 
Aperfeiçoamento de Pessoal de Nível Superior (CAPES) eventos "Qualis Internacional A" na área de Educação. Ao longo dos anos, esta associação tem se projetado como um importante fórum de debates das questões científicas e políticas da área, tornando-se referência para acompanhamento da produção brasileira no campo educacional.

A fim de estabelecer um diálogo com os resultados dos trabalhos levantados no presente estudo, nos reportaremos à Educação Ambiental Hermenêutica (CARVALHO; GRÜN, 2005), abordagem que se situa no campo teórico da hermenêutica filosófica. Tal perspectiva concebe o meio ambiente "enquanto campo complexo das relações entre natureza e sociedade" (CARVALHO; GRÜN, 2005, p. 4) e explicita a necessidade de construirmos uma relação ecológica entre seres humanos e Natureza. Essa relação pressupõe não estarmos fora da Natureza, como afirmava Descartes, nem totalmente imersos nela, conforme postulam algumas leituras da Ecologia Profunda. Em outras palavras, a hermenêutica implica uma relação de encontro e participação entre a natureza e nós, seres humanos, a partir da qual ambos nos constituímos e somos transformados (GRÜN, 1996).

A perspectiva hermenêutica enxerga o ambiente através de uma via compreensiva/interpretativa, que leva em conta a historicidade das questões ambientais e a produção dos sentidos nelas imbricados em lugar de concepções explicativas, reducionistas e objetificadoras da natureza (CARVALHO; GRÜN, 2005). Nessa abordagem, figura "uma educação ambiental compreensiva desde a dimensão do engajamento como pertencimento ao mundo, em contraponto à externalidade que configura o mundo como objeto de um sujeito fora dele" (CARVALHO; GRÜN; AVANZI, 2009, p. 2).

Trata-se de um referencial teórico de posicionamento crítico visualizado na oposição que estabelece à cisão humano-ambiente, herança da ética antropocêntrica instaurada com a modernidade. Essa visão centrada no homem presumia que a libertação da humanidade se daria com o advento da ciência moderna - fundamentada pelas filosofias de Galileu, Bacon e Descartes -, paradigma que pressupunha que o ser humano só poderia ser livre se conhecesse a realidade, e, para obter esse conhecimento, seria necessário distanciar-se dela. É a partir de então que o homem passa a se enxergar como indivíduo independente em relação ao meio e autossuficiente, modo de ser que se sustenta em atitudes de dominação e objetificação da natureza (GRÜN, 1996).

Considerando que a atribuição principal do educador ambiental reside na mediação da relação entre sujeito e ambiente, sendo este designado como seu meio social e natural (MATOS, 2009), defendemos a necessidade de se problematizar cada vez mais a formação de professores/educadores no âmbito da EA. Essa problematização deve englobar diferentes níveis, como o mapeamento de políticas e práticas de EA que têm sido desenvolvidas, o 
investimento que tem sido feito em programas de formação inicial e continuada e a investigação de quais os referenciais que subsidiam esses variados contextos formativos.

\section{Procedimentos metodológicos}

A elaboração deste artigo partiu da leitura dos resumos de todos os trabalhos do GT 22 publicados nos anais eletrônicos das Reuniões Nacionais da ANPEd dos anos de 2009, 2010 e 2011. Em seguida, fizemos a seleção dos artigos cujos resumos mencionavam a formação de professores/educadores na área de Educação Ambiental. Seguindo esse critério, foram analisados, ao todo, 44 resumos: dos cinco trabalhos publicados em 2009 nenhum foi selecionado, dos 21 trabalhos publicados em 2010 quatro foram escolhidos e dos 18 trabalhos publicados em 2011 três se enquadraram na temática em foco. Desse modo, foram selecionados sete artigos para um estudo mais detalhado.

A exploração dos artigos escolhidos foi realizada empregando-se o método de análise de conteúdo. Procedeu-se a uma leitura cuidadosa do material selecionado, de modo que os elementos semelhantes entre si pudessem ser organizados em categorias. A análise por categorias foi dividida em três fases: 1) pré-análise, 2) exploração do material ou codificação e, por fim, 3) tratamento, inferência e interpretação dos resultados (BARDIN, 2004).

A execução desse processo permitiu a sistematização de quatro categorias: Críticas ao reducionismo da EA, EA Crítica como possibilidade de superação da EA vigente, Experiências de EA mediadas pela pesquisa-ação e Desafios na operacionalização da legislação que institui a EA. A organização em categorias permitiu a visualização de como a temática "formação de professores/educadores em EA" tem sido desenvolvida pelos pesquisadores, ou seja, quais são as principais preocupações destacadas pelos autores que têm estudado o assunto nos últimos anos.

\section{Resultados e discussão}

Com base nas categorias identificadas, observou-se que a temática Críticas ao reducionismo da $E A$ é ressaltada em cinco trabalhos (71,4\%), EA Crítica como possibilidade de superação da $\mathrm{E} A$ vigente é o foco de quatro trabalhos $(57,1 \%)$, Experiências de EA mediadas pela pesquisa-ação podem ser identificadas em dois trabalhos $(28,6 \%)$ e três foram os trabalhos que realçaram a questão dos Desafios na operacionalização da legislação que institui a $\mathrm{E} A(42,8 \%)$. A seguir, cada categoria será apresentada e discutida de forma detalhada. 


\section{Críticas ao reducionismo da EA}

Nessa categoria, observaram-se discussões sobre a prevalência de uma Educação Ambiental ingênua e fragmentada nos diversos níveis de ensino e tentativas de tecer críticas ao reducionismo da $E A$, observando-se as relações que esse referencial de EA possui com o sistema capitalista, a mercantilização da educação e o paradigma cientificista que ainda orienta a sociedade na contemporaneidade. $\mathrm{Na}$ verdade, muito do que se tem feito com o nome de Educação Ambiental sequer pode ser considerado como tal, visto que:

A Educação Ambiental surge no Brasil e no mundo Ocidental de modo geral a partir da constatação de que a educação deveria ser capaz de reorientar as premissas do agir humano em sua relação com o meio ambiente. Muitas especulações têm sido feitas no sentido de definir o que é educação ambiental e quais são seus objetivos. A julgar por alguns dos últimos Congressos a tônica parece ser mesmo a diversidade de enfoques. Isso é muito bom para um campo de estudos que já esteve à beira de ser transformado em uma disciplina de "educação ambiental". Se aprovada, essa proposta monodisciplinar e reducionista traria sérios prejuízos para o desenvolvimento da educação ambiental. (GRÜN, 2003, p. 1).

Porém, mesmo com a orientação de que não se deve reduzir a EA ao ensino de práticas sustentáveis isoladas e descontextualizadas do agir humano como um todo, os textos investigados mostram que tal orientação tem sido ignorada em muitas situações.

Aquino (2010) discute a predominância de uma visão fragmentada e descontextualizada dos saberes no âmbito da educação formal, atribuindo essa questão à organização "disciplinar" dos currículos dos cursos de formação de professores. A autora também enfatiza que somente uma formação docente de qualidade pode oferecer condições para que o professor construa uma leitura crítica do mundo, de modo que, "se quisermos que o professor promova situações em que o aluno estruture suas ideias, analise seus próprios processos de pensamento, resolva problemas, é necessário que o professor, em sua trajetória de formação, também tenha vivenciado estas experiências" (AQUINO, 2010, p. 8).

Assim, apesar de haver uma preocupação dos educadores no que diz respeito à contemplação da EA no ensino, as questões ambientais nos currículos das escolas não são tratadas de forma transversal e integrada, prevalecendo práticas pontuais e fragmentadas. Diante desse panorama, Aquino (2010) evidencia a importância de que uma EA, em seu sentido estrito, seja incorporada 
na formação de professores como requisito para a efetivação das questões ambientais no currículo escolar.

Segundo Figueiredo e Silva (2010), apesar de muito se discutir a respeito dos avanços na formação docente, esta ainda apresenta características reprodutivistas e tecnicistas, o conhecimento centrado na figura do professor em uma situação de dominação e submissão, a formação voltada para as demandas do mercado e a fragmentação dos conteúdos. É corriqueiro notar que, quando presente na formação acadêmica, a dimensão socioambiental é veiculada por meio de propostas e ações descontextualizadas, embasadas por uma lógica cartesiana e mecanicista, pautada pela desvinculação entre as questões ambientais e as relações humanas.

De maneira semelhante, Rodrigues e Guimarães (2010) reconhecem que a maioria das práticas de EA é sustentada por uma perspectiva conservadora, que "confunde a Educação Ambiental com ensino de ecologia ou com a descrição dos problemas ambientais; apesar de professores com boas intenções, não há aprofundamento da reflexão em consonância com as práticas [...]" (GUIMARÃES, 2005 apud RODRIGUES; GUIMARÃES, 2010, p. 7).

Silva (2010), ao discutir a formação do educador ambiental oferecida em cursos de pós-graduação lato sensu em EA, questiona a qualidade de tais cursos, uma vez que não há uma lei que obrigue uma avaliação formal de especializações lato sensu - basta que a instituição de ensino superior que as ofereça tenha autorização para funcionar. Nesse sentido, o autor aponta que a falta de critérios que atestem a qualidade desse tipo de curso tem contribuído fortemente para a denominada "mercantilização da educação", fenômeno que trata a educação como mero produto.

Em relação aos cursos com temática socioambiental, essa tendência ainda é mais clara, dada a dimensão mercadológica da palavra sustentabilidade no cenário socioeconômico atual, "onde o ecologicamente correto se transforma em reforço positivo para a construção de marcas, fortalecimento de imagens das indústrias, mascarando assim a inconsistência do capitalismo como ideologia norteadora de uma sustentabilidade socioambiental" (SILVA, 2010, p. 1). A educação mediada por essa tendência, além de mercado rentável para o capital financeiro, configurase, de maneira disfarçada, como replicadora de ideologias que orientam interesses privados e mercantis sobre a sociedade.

Ao atentarem para as concepções que professores da educação básica possuem em relação à EA, Tozoni-Reis, Teixeira e Maia (2011) identificaram o predomínio de concepções baseadas em representações superficiais e difusas acerca do ambiente e da EA. Isso também se reflete na prática docente, que "fica reduzida a [sic] busca empírica de informações, materiais didáticos, recursos humanos e condições de infraestrutura da escola, secundarizando a dimensão 
intelectual mais sofisticada da práxis educativa escolar" (TOZONI-REIS; TEIXEIRA; MAIA, 2011, p. 5). Aliada a essa questão, a partir do referido estudo, os autores constataram que as principais fontes em que os educadores buscam informações sobre a temática ambiental são revistas não científicas e internet, comunicações cujos conteúdos geralmente são superficiais e pouco elaborados. Artigos científicos e demais tipos de publicações acadêmicas corresponderam a menos de $1 \%$ das fontes mais consultadas.

$\mathrm{O}$ reducionismo da $\mathrm{EA}$, de acordo com a perspectiva hermenêutica, constitui "uma visão objetivadora, onde interpretar o ambiente seria captá-lo em sua realidade factual, descrever suas leis, mecanismos e funcionamento" (CARVALHO; GRÜN, 2005, p. 3, destaque dos autores). Em oposição a essa concepção mecanicista, a EA hermenêutica pauta-se pela possibilidade de compreender o meio ambiente de variadas maneiras, as quais dependem da dimensão histórica e dos sentidos produzidos e compartilhados pelo grupo de pessoas que habitam simultaneamente uma mesma região (CARVALHO; GRÜN, 2005).

A diversidade de menções ao reducionismo da Educação Ambiental constatada nos artigos estudados pode ser compreendida a partir do fato de que, conforme aponta Grün (1996), a educação, até a década de 1970, nunca tinha se preocupado de fato com a questão socioambiental, época em que o planeta começou a perceber os impactos da degradação ambiental gerada pelas atividades humanas. Foi a partir da Primeira Conferência das Nações Unidas sobre o Meio Ambiente, ocorrida em Estocolmo no ano de 1972, que a Educação Ambiental começou a ganhar destaque.

Desde então, com o objetivo de reverter a crise ambiental que temos vivenciado, à Educação soma-se o adjetivo Ambiental. Nesse sentido, se considerarmos que a principal motivação de se adjetivar a educação com a palavra "ambiental" repousa nos problemas ambientais desencadeados pelos próprios seres humanos e que, antes disso, o ambiente sequer era uma preocupação para a educação, constata-se que a Educação Ambiental carece de embasamento epistemológico, sendo orientada pela epistemologia do pensamento científico moderno, a qual se sustenta na cisão entre natureza e cultura (GRÜN, 1996).

Portanto, a constatação de que a EA vigente em grande parte da sociedade é reducionista e fragmentada não constitui novidade para os pesquisadores da área. De acordo com Grün (1996, p. 55):

Apesar de que uma atenção considerável tem sido dada à emergência da educação ambiental, raras são as preocupações a respeito das bases conceituais e epistemológicas sobre as quais ela deverá se desenvolver. Temos, assim, um problema sério. Estamos em dificuldades para encontrar uma linguagem ou 
abordagem que nos capacite a falar e compreender as várias dimensões da crise ecológica. Existe hoje uma impossibilidade radical de promover uma educação ambiental.

$\mathrm{Na}$ medida em que o referencial epistemológico constitui a base de um pensamento, entendemos que, sem uma fundamentação desse caráter, qualquer conhecimento tende a ficar restrito à superficialidade. Assim, a questão do reducionismo da EA configura-se, essencialmente, como um problema de ordem epistemológica. Esse panorama evidencia a importância de que a EA seja orientada por um paradigma diferente do que propõe a racionalidade cartesiana, questão que nos remete à abordagem hermenêutica, por privilegiar uma visão ecológica do ser humano e da natureza.

Em consonância com a necessidade de uma EA que abarque o ser humano em sua complexidade, o pensamento hermenêutico busca "desconstruir as dualidades interno/externo e sujeito/ambiente, na direção do que poderíamos chamar de uma epistemologia compreensiva, cuja orientação ecológica evidenciase no reconhecimento das relações simétricas com o ambiente [...]" (CARVALHO; GRÜN; AVANZI, 2009, p. 2).

\section{EA Crítica como possibilidade de superação da EA vigente}

Essa categoria apresenta as contribuições que o referencial teórico da Educação Ambiental Crítica (EA Crítica) - fundamentada na Pedagogia Crítica oferecem para a EA. Por se tratar de uma proposta libertadora e comprometida com a transformação e ressignificação dos valores individualistas, problematiza a forma desarticulada como a EA tem sido desenvolvida e aponta a EA Crítica como possibilidade de superação da EA vigente. Desse modo, em muito se assemelha à categoria anterior, visto que parte da problematização de como a EA tem sido colocada em prática.

Lima e Galiazzi (2011) apontam o paradigma societário atual, orientado por uma subjetividade capitalística e marcado por profundas desigualdades sociais, como responsável pelas mazelas da situação ambiental vigente. Ressaltam que somente a partir de uma problematização crítica desse modo de vida é possível pensar em alternativas para se transformar essa realidade. Apresentam a EA, fundamentada numa visão crítica, como importante nesse processo, visto que, "ao questionar, entre outros aspectos, as relações entre a sociedade e a natureza, a EA fornece subsídios para a compreensão de como essas relações ocorreram no percurso histórico da humanidade, bem como de seus condicionantes" (LIMA; GALIAZZI, 2011, p. 1).

De maneira semelhante, Rodrigues e Guimarães (2010) também apontam as 
relações estreitas existentes entre os problemas ambientais e o modo de produção capitalista, que incita, cada vez mais, um consumo desenfreado. Diante desse problema, sinalizam a necessidade de transformação desse padrão societário, levando o foco para a Educação Ambiental e para uma formação de educadores que seja crítica e que contemple, nessa perspectiva, uma EA emancipatória, já que a atuação desses sujeitos é fundamental na dinamização dos processos de transformações socioambientais.

Rodrigues e Guimarães (2010) ressaltam também que a EA não deve ser entendida como a responsável pela resolução dos problemas ambientais. Em consonância com essa afirmação, Grün (1996) questiona se o âmbito educacional é capaz de dar conta da problemática socioambiental, a qual, antes de qualquer coisa, faz parte de uma crise da cultura ocidental instaurada pelos modos de ser e estar no mundo orientados pelo sistema capitalista vigente.

Também chamando a atenção para os problemas relacionados com o sistema capitalista, Silva (2010) problematiza a formação de especialistas em Educação Ambiental partindo do referencial da EA Crítica, devido ao seu potencial emancipatório e transformador das questões socioambientais vigentes. Em sua investigação, o autor constatou que na maioria das IES privadas - que atuam numa lógica de formação do profissional para o mercado de trabalho em vez de articular o ensino com a pesquisa e a extensão - a questão mercantil sobrepõe-se à questão da formação crítica.

Silva (2010) aponta ainda que, apesar de todos os cursos de especialização em EA pesquisados declararem-se inseridos em uma perspectiva crítica de EA, a análise dos objetivos - voltados para a capacitação para o mercado de trabalho e do conjunto de disciplinas revelou o contrário, visto que a maioria dos cursos possuía componentes curriculares coniventes com a lógica mercantil. Questões como a abrangência do público-alvo e o não aprofundamento nos diversos campos de ação da EA também foram problemas detectados pelo autor.

Figueiredo e Silva (2010), partindo do referencial teórico freireano, apontam como alternativa às formações docentes de bases essencialmente cientificistas e tecnicistas "reconfigurar as diretrizes reprodutivistas em uma dinâmica dialógica, relacional e, portanto, contextualizada; descentralizar a figura do professor e apontar a dinâmica relacional como centro dos processos; sair da lógica opressora e subalterna para vislumbrar uma formação libertadora" (FIGUEIREDO; SILVA, 2010, p. 1). Os autores utilizam, como referências para a discussão de uma proposta de formação docente crítica e reflexiva para o trabalho com a EA, conceitos-chave presentes em diversas obras de Paulo Freire, como humanização, politicidade, reflexão, pesquisa, dialogicidade e dinâmica relacional.

Do mesmo modo, ao relatarem as contribuições que a EA Crítica pode oferecer à formação de educadores ambientais, Rodrigues e Guimarães (2010) 
assinalam princípios da pedagogia freireana, como a não dicotomização da díade docência/discência e o ensinar pautado pela pesquisa, criticidade, ética, coerência, dialogicidade, autorreflexão crítica, "capacidade de ler a complexidade do mundo; abertura para o novo para transformar o presente, não reproduzindo o passado; participação na organização e na pressão para que o novo surja" (GUIMARÃES, 2004, p. 136 apud RODRIGUES; GUIMARÃES, 2010, p. 10).

Nesse sentido, a Educação Ambiental configura-se como campo de disputa entre uma EA conservadora, embalada pela racionalidade dominante, e a EA Crítica, de caráter político, democrático e transformador. Esta tem o papel de resistir ao paradigma cientificista e mecanicista, no qual vigora uma visão dicotômica, separando o ser humano do meio ambiente, colocando-o como entidade central e hierarquicamente superior. Essa visão, através de mecanismos ideologizantes, direciona para uma compreensão única e neutra de mundo, cujo caráter cientificista deslegitima os saberes dos grupos populares (RODRIGUES; GUIMARÃES, 2010).

A perspectiva hermenêutica da EA, na medida em que se apoia na concepção de que nós nos constituímos no movimento de compreensão/interpretação da realidade que nos cerca, também compartilha pressupostos da EA Crítica. Carvalho e Grün (2005, p. 3) confirmam isso ao proporem que o educador ambiental atue como intérprete, estando o sujeitointérprete "diante de um mundo-texto, mergulhado na polissemia e na aventura de produzir sentidos, a partir do seu horizonte histórico". Evidenciam, portanto, a condição de abertura em que o sujeito que se posiciona como intérprete do mundo se encontra, visto que a cada novo contato com o mundo reinterpreta a realidade, a qual se encontra passível de constante ressignificação.

Esse posicionamento de base interpretativa concebido pela hermenêutica filosófica vai ao encontro do referencial freireano, podendo ser visualizado no sujeito crítico, dialógico e consciente, que busca a emancipação e a libertação na relação de abertura que estabelece com o seu ambiente-mundo, partindo da problematização da própria realidade.

\section{Experiências de EA mediadas pela pesquisa-ação}

Essa categoria revela como experiências de EA mediadas pela pesquisa-ação podem contribuir para a efetivação de uma EA voltada para a práxis, sustentando-se no constante diálogo entre ação, reflexão e ação transformadora. Como a pesquisa-ação é uma modalidade investigativa que pressupõe uma compreensão crítica da realidade, cabe ressaltar as aproximações que as formulações teóricas dessa categoria apresentam com a categoria EA Crítica como 
possibilidade de superação da EA vigente.

Lima e Galiazzi (2011) relatam a experiência da Roda de Formação, grupo de formação permanente de professores cuja metodologia baseou-se na pesquisaação participante. A realização de uma Roda de Formação faz menção aos círculos de cultura, proposta de formação coletiva idealizada por Paulo Freire na década de 1960 para a alfabetização de adultos.

A Roda de Formação é salientada pelas autoras como espaço privilegiado para se efetivar uma Educação Ambiental baseada na práxis, no diálogo e na participação ativa dos sujeitos. Nesse sentido, é levando em consideração a própria realidade, numa atitude de valorização da dimensão histórica de cada sujeito, bem como das diferenças individuais entre os participantes, que os saberes socioambientais são construídos e significados. A Roda de Formação tem o principal objetivo de proporcionar aos participantes uma leitura crítica da realidade e, em consonância com os princípios socioambientais, problematizar e transformar a configuração da relação sociedade-natureza (LIMA; GALIAZZI, 2011).

Em relato de experiência sobre a inserção de projetos de Educação Ambiental em um programa de formação continuada de professores, Santos (2011) aponta que a utilização da metodologia da pesquisa-ação mostrou-se muito eficiente, na medida em que propõe uma compreensão para além do estudo de questões ambientais. O conhecimento não é dado, tampouco transmitido; é construído pelos sujeitos a partir das próprias experiências em relação às suas realidades socioambientais. A identificação, compreensão e o solucionamento de questões ambientais locais constituem o foco do processo, exigindo a participação ativa dos atores e contribuindo para a formação cidadã de sujeitos críticos e transformadores, na medida em que se tornam professores pesquisadores.

A partir das possibilidades vislumbradas por esse trabalho, a autora indica que educadores "críticos e reflexivos, com uma postura interdisciplinar, construtivista e comunicacional, capazes de compreender as relações entre sociedade e ambiente" (SANTOS, 2011, p. 1), são essenciais para o trabalho com a temática socioambiental na escola, apontando a relevância de professores que utilizam a pesquisa como possibilidade de reflexão, elaboração crítica e transformação da própria prática docente.

Assim, esses professores pesquisadores, ao atuarem na realidade escolar e social como sujeitos da práxis, num movimento dialético entre as esferas da ação e da reflexão, de certo modo estariam praticando uma espécie de pesquisa-ação, que no âmbito da docência se caracterizaria como "pesquisa-ensino". Esta, considerada uma modalidade da pesquisa-ação, constitui uma prática docente crítica, na medida em que leva o professor a um constante questionamento de sua prática, sendo essa reflexão uma atividade propulsora para a melhoria e a 
inovação das práticas pedagógicas (SANTOS, 2011).

Diante dessas considerações, pode-se constatar que a pesquisa-ação, enquanto intervenção baseada na práxis, compartilha pressupostos da perspectiva hermenêutica. Segundo Carvalho e Grün (2005, p. 3):

Esta perspectiva [hermenêutica] implica ainda [a] recusa da dicotomia entre o plano do pensamento e o da ação. Os sentidos produzidos por meio da linguagem são a condição de possibilidade do agir no mundo. Não há ação possível num vácuo de sentido. Toda ação decorre de certa compreensão/interpretação de algo que faz sentido. Num universo habitado por inúmeras chaves de sentido. Desta forma, assim como interpretar não seria um ato póstumo e complementar à compreensão, agir não corresponderia à conseqüência - enquanto desdobramento, ato segundo ou posterior à reflexão mas a ação estaria implicada no ato mesmo de compreender/interpretar.

O caráter hermenêutico-compreensivo da pesquisa-ação se evidencia na medida em que as relações experienciadas nesse contexto permitem "uma construção mútua dos sentidos da ação, da compreensão/interpretação do mundo e da experiência vivida" (CARVALHO; GRÜN; AVANZI, 2009, p. 5). A atitude de abertura inerente a esse modo de investigação coincide com uma postura compreensiva, destituída de certezas e marcada pela "imprevisibilidade do encontro, os riscos do jogo, a primazia da pergunta sobre a resposta, desde uma relação de pertencimento com o que se dá a conhecer" (CARVALHO; GRÜN; AVANZI, 2009, p. 8).

\section{Desafios na operacionalização da legislação que institui a EA}

Essa categoria apresenta os avanços que a legislação já alcançou ao prever que se contemple a dimensão ambiental em todos os níveis de ensino de maneira integrada, tendo em vista um enfoque transdisciplinar. Por outro lado, mostra que pouco se tem feito para que o cumprimento da lei seja efetivo, apontando que há muitos desafios na operacionalização da legislação que institui a $\mathrm{E} A$.

Aquino (2010) realizou um estudo que investigou como professores do Ensino Fundamental de escolas públicas de um município do interior da Bahia articulam os conteúdos que permeiam a questão ambiental no cotidiano da organização curricular. A pesquisa evidenciou que os professores têm dificuldades em cumprir a determinação legal de inserir a EA nos currículos, visto que reclamaram "dos equívocos da política educacional, que cria leis para revolucionar a educação, mas na prática mantém estruturas que não passam de fábricas de analfabetos" (AQUINO, 2010, p. 7). Além dessas dificuldades, tais 
educadores declararam haver carência de uma boa formação, embora tais problemas não os impeçam de inserir os saberes ambientais no cotidiano da escola.

Figueiredo e Silva (2010) discutem sobre o histórico da inserção da EA na formação docente e de nível superior. Apontam que, já em 1977, recomendações contidas no documento resultante da Conferência Intergovernamental sobre EA, ocorrida em Tbilisi, apresentam a preocupação de inserir a EA no âmbito da formação de professores.

Ainda de acordo com Figueiredo e Silva (2010), no Brasil, em 1981, a instituição da Política Nacional de Meio Ambiente, através da Lei $\mathrm{n}^{\circ}$ 6.938, também demonstra a necessidade de inclusão da EA em todos os níveis de ensino. Em 1992, na ECO-Rio, a aprovação da Carta Brasileira para a Educação Ambiental - que recomenda a inserção da dimensão ambiental nos currículos como forma de viabilizar a EA no nível superior - reitera a urgência em se considerar a EA em todos os cursos superiores. Porém, somente com a decretação da Lei $n^{\circ}$ 9.795/99 houve de fato uma determinação legal da inclusão da EA nos currículos de todas as modalidades de ensino, sendo determinado no Artigo $11^{\circ}$ que "a dimensão ambiental deve constar dos currículos de formação de professores, em todos os níveis e em todas as disciplinas" (BRASIL, 1999, p. 3).

Apesar dos aparatos legais que determinam a inclusão da EA no sistema de ensino, os autores concluem que, na prática, a formação de professores carece de uma compreensão crítica e reflexiva sobre a temática socioambiental. As Diretrizes Curriculares para o Curso de Graduação em Pedagogia não apontam referências expressas à EA e as Diretrizes Curriculares Nacionais para Formação de Professores da Educação Básica nem fazem referência à EA como temática necessária (FIGUEIREDO; SILVA, 2010).

Tozoni-Reis, Teixeira e Maia (2011) apontam que a lei que institui a EA na educação formal, ainda que reforçada por políticas públicas de inserção da questão socioambiental nos diferentes níveis de ensino, não constitui garantia da presença da EA na educação escolar de forma significativa. Os autores atribuem esse problema aos obstáculos enfrentados pelos professores, entre eles a falta de recursos didáticos, infraestrutura e (in)formação adequada, o que dificulta a inserção da EA nos currículos escolares.

A partir da análise da redação da Lei no 9.795/99 (BRASIL, 1999), de modo geral, o que se pode constatar é que pressupostos da EA Crítica e da perspectiva hermenêutica discutidos ao longo deste artigo são contemplados. A Educação Ambiental é conceituada considerando-se valores democráticos, participativos e construídos coletivamente. As dimensões da criticidade, da diversidade cultural, da ética, da cidadania e a necessidade de a EA ser desenvolvida de forma articulada e integrada, vetando-se sua implementação nos currículos como 
disciplina isolada, também estão presentes no documento. Nesse sentido, considerando que a dimensão ambiental tem sido reduzida a sinônimo de natureza e a EA, em grande parte das escolas, apesar de constar nos currículos, restringe-se a práticas isoladas em disciplinas específicas, constata-se que, de fato, a lei não está sendo cumprida.

Ao chamar a atenção para o fato de que a referida lei designa que a EA deve ser amplamente contemplada em todos os níveis de ensino, Grün (2003, p. 1-2) afirma que "a tarefa de cumprir com as demandas e expectativas geradas por essa nova situação torna necessário o debate filosófico sobre a "emergência da Natureza' no currículo". Essa constatação de Grün remete-nos a uma questão ética fundamental, que envolve não apenas a discussão sobre o emergir da natureza nos contextos educativos mas também o posicionamento dos sujeitos perante essa nova conjuntura.

Nesse sentido, cabe nos reportarmos ao pensamento de Rolnik (1994) no que diz respeito ao homem da moral e ao homem da ética que nos habitam. $\mathrm{O}$ âmbito moral corresponderia ao aspecto de nossa subjetividade que se manifesta no plano visível, sendo responsável por identificar e discernir os códigos, os valores e as regras da sociedade, estando a serviço da manutenção da ordem, da estabilidade e do equilíbrio. Já a dimensão ética seria aquela que transita no invisível e que, por isso, "escuta as inquietantes reverberações das diferenças que se engendram em nosso inconsciente e a partir daí nos leva a tomar decisões que permitem a encarnação de tais diferenças em um novo modo de existência [...]" (ROLNIK, 1994, p. 166). Assim, em contraponto ao homem da moral, cuja atividade giraria em torno de manter-nos a salvo do desconhecido, o homem da ética assumiria um modo de ser marcado pela abertura às diferenças e adesão ao caos e à experiência de encontro com a alteridade.

Essa reflexão sobre a moral e a ética torna-se fundamental no debate da regulamentação jurídica da EA, visto que "a lei, por si mesma, não produz adesão e eficácia. Somente quando se compreende a importância do que ela tutela ou disciplina, captando seu sentido educativo, é que ela pode ser transformadora de valores, atitudes e das relações sociais" (LIPAI; LAYRARGUES; PEDRO, 2007, p. 31). De um horizonte hermenêutico, isso implica pensar que o aflorar do homem da ética torna-se cada vez mais necessário para que consigamos atribuir sentido à norma instituída, incorporando-a de forma significativa em nossa experiência. Em outras palavras, devemos superar uma subjetividade que se restrinja ao homem da moral (ROLNIK, 1994), do contrário, corremos o risco de ensaiarmos atitudes mecânicas de mero cumprimento da lei sem uma reflexão sobre o sentido de sua existência.

\section{Considerações finais}


O esforço de tecer um diálogo entre a hermenêutica e os resultados encontrados neste estudo emergiu da possibilidade de encontro que a própria perspectiva hermenêutica dispõe. Encontro no sentido de estabelecimento de uma relação autêntica, implicando uma atitude de lançar-se na experiência, pautada pelo reconhecimento de que só é possível existir no encontro com o outro. Nessa abordagem, vislumbra-se uma EA capaz de romper com concepções educativas orientadas pelo paradigma de cisão humano/natureza, obstáculo epistemológico que se situa no cerne da crise ambiental da contemporaneidade.

Em relação aos subtemas que compuseram o presente trabalho, cabe ressaltar que, apesar de estarem divididos em quatro categorias para organizar e facilitar a compreensão, todos estão intimamente relacionados e compõem uma totalidade que não deve ser compreendida de forma fragmentada. Aliás, como foi amplamente discutido até aqui, a compartimentação dos saberes em EA não é desejável, visto que contribui para a concepção acrítica e ilusória de que o ser humano encontra-se separado do meio onde vive.

Ao centrarmos este estudo na temática "formação de professores/educadores em EA" e depararmo-nos com as categorias Críticas ao reducionismo da $\mathrm{E} A$, EA Crítica como possibilidade de superação da EA vigente, Experiências de EA mediadas pela pesquisa-ação e Desafios na operacionalizaçãa da legislação que institui a $\mathrm{E} A$, pudemos perceber, por meio dos próprios títulos das categorias, o quanto os pesquisadores que se ocupam da temática-foco estão preocupados em denunciar a situação atual do educador ambiental. Consideramos que tal inquietação se deve, principalmente, porque um professor mal formado dificilmente se torna capaz de abordar a EA de forma profícua com seus estudantes, os quais, por sua vez, perdem a oportunidade de entrar em contato com um conhecimento reflexivo e transformador.

Destacamos, portanto, a necessidade de se continuar investindo na produção de conhecimento sobre a formação de educadores aptos a trabalhar os saberes socioambientais, visto que, quanto mais se discutem e se comunicam os conhecimentos produzidos, mais rapidamente eles se tornam acessíveis, podendo cumprir sua função social de contribuir para o avanço do campo de estudos em questão. Ressaltamos, por fim, a hermenêutica filosófica como horizonte de compreensão favorável à construção de uma Educação Ambiental comprometida com as dimensões histórica, política e cultural do ser humano, possibilitando que o homem da ética seja constantemente revelado.

\section{Referências}

AQUINO, Maria Sacramento. As questões ambientais no cotidiano da educação básica: 
políticas públicas, formação do professor e organização curricular. REUNIÃO ANUAL DA ASSOCIAÇÃO NACIONAL DE PÓS-GRADUAÇÃO E PESQUISA EM EDUCAÇÃO, 33., 2010, Caxambu, MG. Anais eletrônicos... Caxambu: ANPEd, 2010. Disponível em: <http://www.anped.org.br/33encontro/internas/ver/trabalhos-gt22>. Acesso em: 14 nov. 2011.

BARDIN, Laurence. Análise de conteúdo. Lisboa: Edições 70, 2004.

BRASIL. Lei número 9.795, de 27 de abril de 1999. Dispõe sobre a educação ambiental, institui a Política Nacional de Educação Ambiental e dá outras providências. Diário Oficial - Imprensa Nacional. Brasília, DF, 1999. Disponível em: $<$ http://portal.mec.gov.br/secad /arquivos/pdf/educacaoambiental/lei9795.pdf $>$. Acesso em: 14 nov. 2011.

CARVALHO, Isabel Cristina de Moura; FARIAS, Carmen R. de Oliveira. Um balanço da produção científica em educação ambiental de 2001 a 2009 (ANPED, ANPPAS e EPEA). REUNIÃO ANUAL DA ASSOCIAÇÃO NACIONAL DE PÓSGRADUAÇÃO E PESQUISA EM EDUCAÇÃO, 33., 2010, Caxambu, MG. Anais eletrônicos... Caxambu: ANPEd, 2010. Disponível em: $<$ http://www.anped.org.br/33encontro/internas/ver/trabalhos-gt22>. Acesso em: 14 nov. 2011.

CARVALHO, Isabel Cristina de Moura; GRÜN, Mauro; AVANZI, Maria Rita. Paisagens da compreensão: contribuições da hermenêutica e da fenomenologia para uma epistemologia da educação ambiental. Cad. Cedes, Campinas, v. 29, n. 77, p. 99-115, jan./abr. $2009 . \quad$ Disponível em: <http://www.scielo.br/pdf/ccedes/v29n77/a07v2977.pdf>. Acesso em: 06 ago. 2012.

CARVALHO, Isabel Cristina de Moura; GRÜN, Mauro. Hermenêutica e educação ambiental: o educador como intérprete. In: FERRARO JÚNIOR, Luiz Antonio (Org.). Encontros e Caminhos: Formação de Educadoras(es) Ambientais e Coletivos Educadores. Brasília: Ministério do Meio Ambiente, Diretoria de Educação Ambiental, 2005. Disponível em: <http://www.isabelcarvalho.blog.br/pub/capitulos/hermeneutica_edu.pdf $>$. Acesso em: 16 nov. 2011.

FIGUEIREDO, João Batista de Albuquerque; SILVA, Maria Eleni Henrique da. Formação do(a) educador(a) ambiental numa perspectiva dialógica e relacional. REUNIÃO ANUAL DA ASSOCIAÇÃO NACIONAL DE PÓS-GRADUAÇÃO E PESQUISA EM EDUCAÇÃO, 33., 2010, Caxambu, MG. Anais eletrônicos... Caxambu: ANPEd, 2010.2 Disponível em: <http://www.anped.org.br/33encontro/internas/ver/trabalhos-gt22>. Acesso em: 14 nov. 2011.

GRÜN, Mauro. Ética e educação ambiental: a conexão necessária. Campinas: Papirus, 1996. A outridade da natureza na Educação Ambiental. REUNIÃO ANUAL DA ASSOCIAÇÃO NACIONAL DE PÓS-GRADUAÇÃO E PESQUISA EM 
EDUCAÇÃO, 26., 2003, Poços de Caldas, MG. Anais eletrônicos... Poços de Caldas: ANPEd, 2003. Disponível em: <http://www.anped.org.br/reunioes/26/inicio.htm>. Acesso em: 14 nov. 2011.

LIMA, Cleiva Aguiar de; GALIAZZI, Maria do Carmo. O diário em roda na educação ambiental. REUNIÃO ANUAL DA ASSOCIAÇÃO NACIONAL DE PÓSGRADUAÇÃO E PESQUISA EM EDUCAÇÃO, 34., 2011, Natal, RN. Anais eletrônicos... Natal: ANPEd, 2011. Disponível em: $<$ http:/ /34reuniao.anped.org.br/index.php?option $=$ com_content\&view $=$ article\&id $=135$ :trabalhos-gt22-educacao-ambiental\&catid=47:trabalhos\&Itemid=59>. Acesso em: 14 nov. 2011.

LIPAI, Eneida Maekawa; LAYRARGUES, Philippe Pomier; PEDRO, Viviane Vazzi. Educação ambiental na escola: tá na lei... In: MELLO, Soraia Silva de, TRAJBER, Rachel (Org.). Vamos cuidar do Brasil: conceitos e práticas em educação ambiental na escola. Brasília: Ministério da Educação, Coordenação Geral de Educação Ambiental: Ministério do Meio Ambiente, Departamento de Educação Ambiental: UNESCO, 2007. p. 23-32. Disponível em: <http://portal.mec.gov.br/dmdocuments/publicacao3.pdf\#page=24>. Acesso em: 01 jun. 2012.

MATOS, Mauricio dos Santos. A formação de professores/as e de educadores/as ambientais: aproximações e distanciamentos. Pesq. Educ. Ambient., v. 4, n. 2, p. 203-214, 2009. Disponível em: <http://www.revistasusp.sibi.usp.br/pdf/pea/v4n2/14.pdf>. Acesso em: 10 ago. 2012.

RODRIGUES, Jessica do Nascimento; GUIMARÃES, Mauro. Educação ambiental crítica na formação do educador: uma pedagogia transformadora. REUNIÃO ANUAL DA ASSOCIAÇÃO NACIONAL DE PÓS-GRADUAÇÃO E PESQUISA EM EDUCAÇÃO, 33., 2010, Caxambu, MG. Anais eletrônicos... Caxambu: ANPEd, 2010. Disponível em: <http://www.anped.org.br/33encontro/internas/ver/trabalhos-gt22>. Acesso em: 14 nov. 2011.

ROLNIK, Suely. Cidadania e alteridade: O psicólogo, o homem da ética e a reinvenção da democracia. In: SPINK, Mary Jane Paris (Org.). A cidadania em construção: Uma reflexão transdisciplinar. São Paulo: Cortez, 1994. p. 157-176.

SANTOS, Vânia Maria Nunes dos. Estudo do ambiente local, ensino em geociências e cidadania: a contribuição de projetos de educação ambiental à aprendizagem social. REUNIÃO ANUAL DA ASSOCIAÇÃO NACIONAL DE PÓS-GRADUAÇÃO E PESQUISA EM EDUCAÇÃO, 34., 2011, Natal, RN. Anais eletrônicos... Natal: ANPEd, 2011.

Disponível

em:

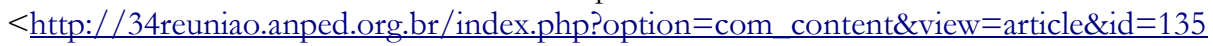
:trabalhos-gt22-educacao-ambiental\&catid=47:trabalhos\&Itemid=59>. Acesso em: 14 nov. 2011.

SILVA, Fábio Alves Leite da. Lato Sensu em Educação Ambiental: uma análise crítica. REUNIÃO ANUAL DA ASSOCIAÇÃO NACIONAL DE PÓS-GRADUAÇÃO E PESQUISA EM EDUCAÇÃO, 33., 2010, Caxambu, MG. Anais eletrônicos... Caxambu: 
ANPEd, 2010.2 Disponível em: <http://www.anped.org.br/33encontro/internas/ver/trabalhos-gt22>. Acesso em: 14 nov. 2011.

TOZONI-REIS, Marilia Freitas de Campos; TEIXEIRA, Lucas André; MAIA, Jorge Sobral da Silva. As publicações acadêmicas e a educação ambiental na escola básica. REUNIÃO ANUAL DA ASSOCIAÇÃO NACIONAL DE PÓS-GRADUAÇÃO E PESQUISA EM EDUCAÇÃO, 34., 2011, Natal, RN. Anais eletrônicos... Natal: ANPEd, 2011.

$<$ http:/ /34reuniao.anped.org.br/index.phpoption=com_content\&view =article\&id $=135: t$ rabalhos-gt22-educacao-ambiental\&catid=47:trabalhos\&Itemid=59>. Acesso em: 14 nov. 2011.

WITTER, Carla. Produção Científica e Educação: análise de um periódico nacional. In: WITTER, Geraldina Porto (Org.). Metaciência e psicologia. Campinas: Alínea, 2005. p. 137154.

Artigo recebido em 25/07/2011

Artigo aprovado em 11/09/2011 